\title{
Aflatoxins in roasted peanut in Khartoum a hidden and notorious risk to children
}

\author{
Esameldin Bashir Mohamed Kabbashi ${ }^{1 *}$, Mohamed Ali Elnour ${ }^{2}$, Safa Hassan Ahmed ${ }^{3}$ \\ 'Department of Grain Technology, The National Food Research Center, Ministry of Higher Education and Scientific Research, \\ Khartoum, Sudan, ${ }^{2}$ Department of Animal Product Technology, The National Food Research Center, Ministry of Higher Education \\ and Scientific Research, Khartoum, Sudan, ${ }^{3}$ Department of Oil Seed Technology, The National Food Research Center, Ministry of \\ Higher Education and Scientific Research, Khartoum, Sudan
}

\begin{abstract}
Received: 26.12 .2016
Accepted: 16.04 .2017

Published: 24.04 .2017

*Address for correspondence:

Esameldin Bashir Mohamed

Kabbashi, The National

Food Research Center,

Ministry of Higher

Education and Scientific

Research, Khartoum, Sudan.

E-mail: esameldinkabbashi@

gmail.com
\end{abstract}

\begin{abstract}
Aflatoxins are secondary metabolites of about twenty species of the genus Aspergillus. The most important of these species is Aspergillus flavus which was reported for the first time and referred as responsible for the $X$ - turkey disease in 1960 in Great Britain which later on named aflatoxicosis. These toxins pose a limitless risk to man and his domestics by causing a number of diseases and carcinomas. However, since the production of these toxins is rather inevitable accordingly, an interdisciplinary management is the answer for managing them. The management of these toxins includes preharvest and postharvest measures such as good agricultural practices, check of imports, exports, food and feed stuffs, specifying tolerable and action limits and curing by suitable methods. This experiment aimed at having a rapid check for the total aflatoxins in roasted peanut in samples (five groups and 25 in total) collected from the three main cities of the triangular capital Khartoum (Khartoum proper, Khartoum North, and Omdurman). A rapid check of aflatoxins has a lot of merits and edge over the other laboratory methods. A total of 25 samples of roasted peanut were checked using Aflacheck ${ }^{\circledR}$ test kids (the method used enabled checking $10 \mathrm{ppb}$ total aflatoxins in test samples). Readings revealed that the contamination percentage was $60 \%$ for each of the sample groups collected from the two sites in Khartoum proper and $100 \%$ for the sample groups collected from two sites in Khartoum North and Omdurman, separately. Statistical analysis showed a significant difference in contamination (at $5 \%$ confidence level) between the results from Khartoum proper from one side and the samples collected from Khartoum North and Omdurman areas in the other side. However, the overall contamination percentage was $84 \%$. These results, collectively, are alarming (0 tolerance) for a deadly health risk of this roasted peanut contaminated with aflatoxins to consumers of who the majority are children.
\end{abstract}

KEY WORDS: Aflatoxins, Aflacheck ${ }^{\circledR}$, children, roasted peanut, risks, Khartoum

\section{INTRODUCTION}

\section{Aflatoxins}

Aflatoxins are secondary metabolic products that contaminate food stuff. They are difuranocoumarins and the lactone they have qualifies them as important carcinogens and being potent alkylating products (Pack and Islami, 1970). These toxins are produced by some members of the genus Aspergillus (>20 species) the most common of which are Aspergillus flavus and Aspergillus parasiticus and two species from the genus Aschersonia (Aschersonia coffeae and Aschersonia morginita) (Varga et al., 2015). However, this genus Aspergillus has 344 reported species (Frisvad, 2014). These toxins include some major ones such as aflatoxin B group (B1 and B2) and G group (G1 and G2) beside their penultimate precursor Sterigmatocystin which is also toxic and carcinogenic as they are (Varga et al., 2015). However, besides milk aflatoxins AFM1 and AFM2 (Varga et al., 2015) there are a number of products from the metabolism of the major aflatoxins mentioned that include:

1. 8,9-epoxide which is a product of oxidation of AFB1 in human liver and it turns rapidly to dihydrodiol by nonenzymatic hydrolysis and slowly into AFB1 dialdehyde (Johnson et al., 1996).

2. AFB1 dialcohol is produced by the conversion of AFB1 dialdehyde in a reaction mediated by AFB1 reductases at pH 10 (Guengrich et al., 2001). 
3. Aflatoxin Q1 which is a hydroxyl metabolite of AFB1 and produced in vitro by samples of human liver preparations and 5 species of non - human pirates (Yourtee et al., 1987). The maximum amount of this toxin produced can reach $10 \%$ of AFB1 used. It is produced by microsomal hydroxylation of AFB1 of chicken and ducks (Smith and Henderson, 1991).

4. Aflatoxin Q2 which is a minor metabolite of AFB2 from in vitro preparations of the liver of rat, mouse, and human (Roebuck et al., 1978).

5. Aflatoxicol1 Aflatoxicol2 are in vitro metabolites of AFB2 by post-mitochondrial supernatant fractions of duck, rat, mouse, and human (Roebuck et al., 1978).

6. Aflatoxin P1 is a product of detoxification of AFB1 by demethylation and is 15 folds less toxic than its parent molecule (Buchi et al., 1973).

7. Aflatoxin $\mathrm{P} 2$ is a product of metabolism of $\mathrm{AFB} 2$ in rat, mouse and human liver preparations (Roebuck et al., 1978).

8. Aflatoxin M1 and aflatoxin M2, metabolites of AFB1 and AFB2, respectively. They are first reported in milk, $m$ stands as a designation for that (Nogaim, 2014).

It may be worth noting that AFB2 metabolites in vitro include small amounts of AFM1 and AFM2 as well (Roebuck et al., 1978).

\section{Pathogenicity of Aflatoxins}

A high risk was reported from contamination with these toxins which resulted in aflatoxicosis, acute digestive distortion and some chronic complications that included malignancy and hepatoma (CAST, 1979; Diener et al., 1987). However, exposure to high levels of aflatoxins in food leads to severe malnutrition, kwashiorkor and stunted growth in children in a lot of developing countries (Gong et al., 2002). A lot of countries now have their own action levels for aflatoxins in food and feed. That is, USFDA set the allowed total aflatoxins level up to $20 \mathrm{ppb}$ in food and feed and only $0.5 \mathrm{ppb}$ for aflatoxin M1 in milk (Varga et al., 2015).

\section{Aflatoxins in Sudan}

The importance of aflatoxins in peanut in Sudan stems from the huge production ( $>$ million tons/annum), its high consumption (as food and feed) and as an important export (Mehan et al., 1989). Peanut is very susceptible to aflatoxin contamination, and this fact is manifested by a lot of literature of research. That is, in Sudan 100\% contamination by aflatoxins was reported in 43 samples of peanut butter from Khartoum state (Elzubair et al., 2011). In addition, a lot of work preceded this experiment include the following references (Mehan et al., 1989; Ahmed et al., 1989; Singh et al., 1989; Elamin et al., 1988; Habish et al., 1971). However, this work was done to perform a rapid check for total aflatoxins in roasted peanut sold as pass the time spinach in greater Khartoum. It was done in a comprehensive training for the store managers of the Agricultural Bank of Sudan.

\section{MATERIALS AND METHODS}

\section{Materials}

Aflacheck ${ }^{\circledR}$ kits of Vicam, Waters Incorporation, USA; glassware (beakers, flasks, glass rods, funnels, measuring cylinders etc., ); digital pipettes, digital sensitive balance, pestle and mortar, small plastic bags, roasted peanut beans, absolute alcohol, and distilled water.

\section{Methods}

Roasted peanut samples (25 in number) were collected from retailers in five sites which were namely central and local whole markets in Khartoum proper; Koko and Geraif East, Khartoum North, and Shohada in Omdurman. A ground weight of $5 \mathrm{~g}$ was taken from each sample using a digital sensitive balance and kept in a small plastic bag for the test. The procedure of Vicam (Vicam, 2016) was followed in this test. The steps of this test are as follows:

\section{Sample extraction}

1. Five grams of the test sample weighed and added to a 40 extraction tube.

2. $10 \mathrm{ml}$ of $70 \%$ methanol were taken with a $10 \mathrm{ml}$ graduated cylinder and poured into a $40 \mathrm{ml}$ extraction tube.

3. The $40 \mathrm{ml}$ extraction tube was then covered and the mixture was shaked well by hand for $1 \mathrm{~min}$.

4. The mixture then was left to stand for $3 \mathrm{~min}$.

\section{Aflacheck $\circledast$ procedure}

1. Strip test dilution tube was placed in the paper rack found in the kit box.

2. Distilled water, $250 \mu \mathrm{L}$, was added to the strip test dilution tube using a $250 \mu \mathrm{L}$ strip test pipettor.

3. Sample extract, $250 \mu \mathrm{L}$, was transferred to the strip test dilution tube by a new strip test pipettor.

4. The solution was mixed by capping the strip test dilution tube and agitating by hand.

5. Aflacheck ${ }^{\circledR}$ strip test (arrows pointing down) was inserted into the solution tube and left to develop.

6. The result was taken negative when two lines (of the test and the control) noticed and positive when only one line (of the test) observed in the test strip. The 
time needed is estimated as $3 \mathrm{~min}$.

7. The time of development was up to $5 \mathrm{~min}$ for a better result. If after 5 min no test line appears then the results can be interpreted as positive.

8. When no line observed the test was repeated using another test strip.

The Afalcheck ${ }^{\circledR}$ test strip reflected one line in three samples from each of the two groups of samples from the two sites in Khartoum proper whereas all the other test samples showed the same result. However, SPSS statistics program was used for the significance at $5 \%$ level.

\section{RESULTS AND DISCUSSION}

The results of this test of rapid aflatoxin check by Aflacheck ${ }^{\circledR}$ are summarized in Table 1 . The contamination percentage of the test samples was $60 \%$ for the groups from Khartoum proper whereas the corresponding results for all the other test samples were $100 \%$. The overall contamination percentage was $84 \%$. The difference between the results of the experiment is significant at 5\% level. However, samples collected from rainfed areas of Western Sudan showed a high level and percentage of contamination being $>1000 \mathrm{ppb}$ and $94 \%$, respectively (Ahmed et al., 1989). A contamination of $2.7-7 \%$ of irrigated groundnut was reported in seed left in the soil for 6 weeks postharvest, yet they were found free of aflatoxins. In addition, an infection by $56.4-69.8 \%$ and a contamination of $18.21 \mathrm{ppb}$ with aflatoxins were recorded in seeds predisposed to $A$. flavus by wilt diseases and insects such as white grub and termites (Ahmed et al., 1989). Moreover, 100\% contamination with aflatoxins $B$ and $G$ groups was recorded in 43 samples of peanut butter from Khartoum state (Elzubair et al., 2011). These results reflect the high level of aflatoxin contamination in peanut which agree with the findings of this research. However, a number of methodologies are available for aflatoxin check. These include enzyme linked immunosorbet assay (ELISA), electromechanical and optical dependent methods which represented by chromatography, ultraviolet - absorption, spectrometry, fluorescence, and immunochemical assay methods

Table 1: Aflacheck ${ }^{\circledR}$ test results of roasted peanut

\begin{tabular}{llccc}
\hline Sample area & Sample site & $\begin{array}{c}\text { Group } \\
\text { number }\end{array}$ & $\begin{array}{c}\text { Positive } \\
\text { samples }\end{array}$ & Contamination (\%) \\
\hline Khartoum proper & Central market & 1 & 3 & $60^{\mathrm{a}}$ \\
-Do- & Local market & 2 & 3 & $60^{\mathrm{a}}$ \\
Khartoum North & Koko & 3 & 5 & $100^{\mathrm{b}}$ \\
-Do- & Geraif East & 4 & 5 & $100^{\mathrm{b}}$ \\
Omdurman & Shohada & 5 & 5 & $100^{\mathrm{b}}$ \\
Total & & & 21 & 84 \\
\hline
\end{tabular}

*Figures bear different letter are significantly different at 5\% level
(Espinosa-Calderón et al., 2016). However, the action level of aflatoxins differs with different organizations. That is, the common limits (in $>75$ countries) of AFB1 and total aflatoxins in foods are 5 and $10 \mathrm{pp}$, respectively. In the European Community the corresponding figures are 2 and $4 \mathrm{ppb}$ which are more restrictive (Herzallah, 2009; Cucci et al., 2017). All these control and inspection formalities need sometimes a rapid check which has a lot of merits over the other laborious laboratory analysis procedures for aflatoxins. That is, it is rapid and needs no complicated deeds nor extended time and a lot of training to get results besides being far cheaper compared to the other laboratory ones. However, this is manifested by a lot of research such as the research that dealt with the evaluation of five commercially used aflatoxin test kits for the check of aflatoxins in maize. These kits in spite of being approved by the US Department of Agriculture yet they were evaluated against high-performance liquid chromatography results using more than $50 \mathrm{~g}$ of samples. The results revealed no significant difference between the methods evaluated (Susie et al., 2013). A lot of brands of ELISA aflatoxin check kids are available which include Aflacheck $^{\circledR}$, AgraQuant $^{\circledR}$, Rida ${ }^{\circledR}$ Smart App., SmarKit ${ }^{\circledR}$, etc., This information displays the importance of the rapid and in site test for aflatoxins in food and feed. However, this research fulfilled also some primary important issues of research, training, and extension for trainers in this concern. That is, the check of aflatoxins in roasted peanut, a pass the time spinach, that represents a popular food and for children in particular.

\section{CONCLUSIONS}

The results obtained in this study reflect a high contamination of roasted peanut with aflatoxins which are very alerting and alarming for the importance of controlling these deadly carcinogens. However, this study also satisfied the training needs about the use of Aflacheck ${ }^{\circledR}$ test for the store managers of the Agricultural Bank of Sudan who will, by their turn, transfer this technology to other beneficiaries and will elevate the safety level of food, using available and easy to use method, at least for a very important and susceptible sector of the Sudanese community to these carcinogens, the children.

\section{ACKNOWLEDGMENTS}

The cooperation of Mr. Mohamed Ali Masaad and the Higher Administration of the Agricultural Bank of Sudan is really appreciated. We are indebted to Professor Abdallah Satti of the ENRRI, NCR, Khartoum and his colleagues. Thanks are extended to Mr. Hamza Omer who made 
the Aflacheck ${ }^{\circledR}$ kits available from London. We are also grateful to Mr. Manal Khattab for her effort in preparing some test materials.

\section{REFERENCES}

Ahmed NE, YounisYM, Malik KM. Aspergillus flavus Colonization and Contamination of Groundnut in sudan. Proceedings of the International Workshop, 6-9 October, 1987; 1989.

Buchi G, Spitzner D, Paglialunga S, Wogan GN. Synthesis and toxicity evaluation of aflatoxin P1. Life Sci 1973;13:1143-9.

CAST. Aflatoxins and other Mycotoxins: An Agricultural Perspective CAST Report No. 80. Ames, IA: Council of Agricultural Science and Technology; 1979.

Cucci C, Mignani A, Dall' Asta C, Pela R, Dossena A. A portable fluorometer for the rapid screening of M1 aflatoxin. Sens Actuators B Chem 2007;126:467-72.

Diener UL, Cole RJ, Sanders TH, Payne GA, Lee LS. Epidemiology of aflatoxin formation by Aspergillus flavus. Annu Rev Phytopathol 1987;25:249-70.

Elzubair AO, Salih AO, Suliman SA, Adam AA, Elhussein AM. Aflatoxins in peanut butter in Khartoum state, Sudan. Mycotoxin Res 2011;27:1836.

Espinosa-Calderón A, Contreas-Medina LM, Muňoz-Heutra RF, Millán-Almaraz JR, González RG, Torres-Pacheco I. Methods for Detection and Quantification of a Flatoxins; In: Torres-Pachero I. Aflatoxins-Detection, Measurement and Control. Rijeka, Croatia: InTech Publisher; 2011. p. 376.

Elamin NH, Abdelrahman AM, Khalid AE. Aflatoxin contamination of groundnut in Sudan. Mycopathologia 1988;104:25-31.

Frisvad JC. Taxonomy, chemodiversity, and chemoconsistency of Aspergillus, Penicillium, and Talaromyces species. Front Microbiol 2014;5:773.

Gong YY, Cardwell K, Hounsa A, Egal S, Turner PC, Hall AJ, Wild CP. Dietary aflatoxin exposure and impaired growth in young children from Benin and Togo: Cross sectional study. Br Med J 2002;325:20-1.

Guengrich FB, Cai H, McMahon M, Hayes JD, Sutter TR, Groopman JD, et al. Reduction of aflatoxin B1 dialdehyde by rat and human Aldo - Keto reductases. Chem ResToxicol
2001;14:727-37.

Habish HA, Abdulla MH, Broadbent JH.The incidence of aflatoxin in Sudanese groundnuts. Trop Sci 1971;XIII:279-87.

Herzallah S. Determination of aflatoxins in eggs, milk, meat, and meat products using HPLC fluorescent and UV detectors. Food Chem 2009;114:1141-6.

Johnson WW, Harris TM, Guengrich FP. Kinetics and mechanism of hydrolysis of aflatoxin B1 exo-8, 9 - Epioxide and rearrangement of the dihydrodiol. J Am Chem Soc 1996;118:8213-20.

Mehan VK, McDonald D, Haravu IJ, Jayanthi S. The Groundnut Aflatoxin Problem: Review and Literature Database. Patancheru, AP, India: ICRISAT; 1989. p. 324-502.

Nogaim QA. Aflatoxins M1 and M2 in dairy products. J Appl Chem 2014;2:14-25.

Pack GT, Islami AH. Recent results in Cancer Research. New York, Heidelberg-Berlin: Springer-Verlag; 1970. p. 61.

Roebuck BD, Siegel WG, Wogan G. In vitro metabolism of aflatoxin B2 by animal and human liver. Cancer Res 1978;38:999-1002.

Smith JE, Henderson RS. Mycotoxins and Animal Foods. Boca Raton: CRC Press Inc.; 1991.

Singh B, Khalid AS, Magboul B, Okezie BO, Anderson JC, Wheelock GC, et al. Aflatoxin contamination of groundnuts with special reference to Sudan and some Caribbean countries. In: Proceedings of the International Workshop, 6-9 October 1987. Patancheru, AP, India: ICRISAT; 1989. p. 324-502.

Susie YD, Kyung-Min L, Weili JB, Timothy JH. Aflatoxin risk management in texas: Test kit approval for maize. IJRS 2013;1:15-22.

Varga J, Baranyi N, Chandrasekaran M,Vágvölgyi C, Kocsubé S. Mycotoxin producers in the Aspergillus genus: An update. Acta Biol Szeged 2015;59:151-67.

Vicam. Manual:Aflacheck; 2016. Available from: http: / /www. vicam.com/aflatoxin-test-kit/aflachek/aflacheck.

Yourtee DM, Bean TA, Kirk-Yourtee CL. Human aflatoxin B1 metabolism: An investigation of the importance of aflatoxin $\mathrm{Q}$ as a metabolite of hepatic post - Mitochondrial dried fraction. Toxicol Lett 1987;38:312-24. 